\title{
On Li Hongzhang's Coastal Defense Measures Under the Sino-Japanese Conflict in the 1870s
}

\author{
Peijie Shi
}

\begin{abstract}
International Chinese education in Macau University of Science and Technology, Macau, 999078, China Email:1163348311@qq.com
\end{abstract}

\begin{abstract}
Since the "Meiji Restoration", Japan has gradually formulated a powerful maritime force. In May 1874, Japan invaded Taiwan Province from the East China Sea, and the Qing government sent troops to fight back. In October 1874, the negotiations between China and Japan were concluded and the Sino-Japanese Convention of Peking was signed. However, the concession of the Qing government did not restrain Japan's ambition to expand. Contrarily, Japan conserved energy and strength, which paved the way for its future actions of "abolishing the feudal Han and introducing prefectures" in Ryukyu, aggression against North Korea, and forced the Qing government to cede Taiwan and its affiliated islands after the First Sino-Japanese War 1894-1895. Li Hongzhang was the core figure of the coastal defense faction in the late Qing Dynasty. After the conflict between China and Japan in the 1870s, he submitted a memorial Discussion on Coastal Defense to the Qing government and explained six of his coastal defense measures in detail. He has an inescapable responsibility and an indelible contribution to the issue of coastal defense against Japan. Through the study, we can have a preliminary understanding and an objective evaluation of Li Hongzhang's coastal defense measures and their influence on the later historical trend.
\end{abstract}

Keywords: Li Hongzhang, Coastal defense measures, Japanese war of aggression against Taiwan

\section{RESEARCH ON LI HONGZHANG AND THE CAUSES OF HIS COASTAL DEFENSE MEASURES}

Li Hongzhang (1823-1901) was born in Hefei, Anhui Province. His life rose and fell because of diplomacy. In his early years, with the support of Zeng Guofan, he carried out a series of foreign affairs activities with foreigners. With excellent diplomatic means, he saved a lot of interests and face for the Qing Dynasty, which won him the trust and respect of the Qing Dynasty. In middle age, he highly appreciated the idea, "learning advanced technology from barbarians in order to oppose barbarians" of Lin Zexu, Wei Yuan and etc., launched Westernization Movement, and planned for the coastal defense matters, which demonstrated his dedication. In his later years, as the main planner and executor of the coastal defense system at that time, he went to Japan to sign the Treaty of Shimonoseki at an age of over 70 after the total collapse of the coastal defense system during the Sino-Japanese War 1894-1895.

This paper takes Li Hongzhang's coastal defense measures under the background of the Sino-Japanese conflict in the 1870 s as the research object, traces the causes of the formation of Li Hongzhang's coastal defense measures, and analyzes the advantages and disadvantages of Li Hongzhang's coastal defense measures on the present national defense construction in China, as well as the influence on the historical trend.

\section{REASONS FOR THE FORMATION OF LI HONGZHANG'S COASTAL DEFENSE MEASURES}

The 1870s was an important period for the formation and implementation of Li Hongzhang's coastal defense measures. The conflict between China and Japan over territorial occupation and counter-occupation prompted the late Qing government to plan and establish China's offshore marine defense system. Through the exploration of the background and reasons for Li Hongzhang's coastal defense measures, we can better understand the importance of these measures' formation and the difficulty of their implementation. 


\subsection{Opium War-Transition from Emphasis on Traditional Land Frontier Defense to Equal Attention to Coastal and Land Frontier Defense}

Since ancient times, China has attached great importance to the "Land Power", and the geographical area and location of the land are very superior. Before the Opium War, the threat of foreign invasions from the sea was rare. Based on this relatively safe geographical environment, the Chinese people's "awareness of potential risks", especially the "awareness of potential risks from the ocean" was extremely weak. "For the feudal dynasties in ancient China, the threat generally came from the prairie nomads of the north and the later rising Tsarist-Russian Empire. Therefore, the military preparation in ancient China mainly focused on the land frontier defense, and ancient China was an era in which thought of land power greatly developed."

The fiasco of the Qing government in the two Opium Wars was the result of the long-term implementation of the policy of seclusion which was the root cause of China's ignorance of the world's development and its tendency to be complacent, conservative and backward in those years. Therefore, the Qing government, which was frequently beset by civil and foreign wars, had to put the construction of coastal defense on the agenda, and naturally, Li Hongzhang's Discussion on Coastal Defense was also taken seriously.

\subsection{The "Japanese War of Aggression against Taiwan" in the 1870s -- the "Trigger" for the Implementation of the Coastal Defense Measures}

After Japan's occupation of Ryukyu in 1879, Li Hongzhang's thoughts on coastal defense changed greatly and his emphasis on coastal defense even influenced the reconstruction of national defense system in the late Qing Dynasty.

(1) Japan's territorial aggression against China was caused by its dependence on China's resources. As early as 1870, China and Japan had signed Sino-Japanese Provisions of Cordial Relations in September 1871. However, Japan's geographic location led to a shortage of natural resources. After the Meiji Restoration, Japanese industry has made great progress, yet became more and more dependent on resources. Consequently, Japan has turned its eyes to its former ally, China.

(2) Benefited from Japan's long management of its maritime interests. Given that in the late Qing Dynasty, the government was shaky and decadent, which had little time to deal with other affairs in face of internal and external problems, and for hundreds of years, Ryukyu was governed by Japan, of which provocation has been long-planned, the Qing government had to pay 500,000 taels of silver to Japan in October 1874, and signed the
Sino-Japanese Convention of Peking, acknowledging that the Japanese invasion of Taiwan "was originally an act for protecting people, and China did not point out that it was wrong.".

At this time, Li Hongzhang began to put the coastal defense measures presented in the memorial into practice. Under the suggestion of Li Hongzhang, the Qing court gradually incorporated the coastal defense construction into the national defense system construction as an important part.

\section{LI HONGZHANG'S COASTAL DEFENSE MEASURES}

Japan's coveting for China's territory of the late Qing Dynasty, especially the invasion of the sea, gradually aroused the attention and vigilance of the Qing government. In March 1879, Japan followed the provisions of the Sino-Japanese Convention of Peking that the invasion of Taiwan was the "protection of the people", and abolished the feudal Han and introduced prefectures in Ryukyu, totally taking the island for itself. Therefore, Li Hongzhang "put forward six specific measures, including training soldiers, upgrading weapons, shipbuilding, raising fund, employing talents and persistence. The main purpose of political reform was to reform the military system and build a modern navy. The major objective of employing talents indicated reforming the imperial examination system and cultivated new qualified personnel."

\section{1. "Training Soldiers"}

"Training soldiers" is the core of coastal defense. First is the formation of three naval forces: Beiyang, Dongyang, Nanyang. How to train a new navy is the top priority of Li Hongzhang's concerns while his coastal defense thought became increasingly mature.

From this point on, Li Hongzhang was aware of the different methods of training and fighting between the navy and the ground force. The so-called "different professionals have their own specialty" combining with the strategy of "easy to hold but difficult to attack" determined his mind that only by further developing the naval forces of the Qing government, could more than 30,000 kilometers' China's coastline defense system be build up against the increasingly powerful Japanese maritime forces, making China's coastal defense "difficult to attack" instead of being easily broken in by the foreign powers in like the First Opium War. While the role of "easy to defend" was played by the new army, if the island chain was broken by the enemy, the army and navy stationed ashore should corporate with the offshore navy, to defend the maritime gateway and resist the enemy at sea. 
In addition, emergency response ability in wartime benefited from the rigorous pre-war training. As $\mathrm{Li}$ Hongzhang put it, "In times of need, only drill and build fortresses; in times of need, only prepare for guerrilla units, and no decentralized movement is allowed". These words emphasized the importance of training in discipline.

\section{2. "Upgrading Weapons"}

"Upgrading Weapons" is the action on "implements". In the memorial, Li Hongzhang explained the advantages and disadvantages of various Western weapons in detail, and more importantly, identified the gap between Chinese and the Western powers in the "implements". He praised the foreign gun that "as for the foreign gun, western countries used backdoor guns because of its ingenuity, high speed and long range. Their old front-door guns were sold at a low price in China, and such guns were always despised by other outsiders." But it was still difficult for the officers and soldiers of the Qing Dynasty to master the techniques of using such backward weapons. Li Hongzhang realized this practical problem, "Sometimes trained with Remington, the soldiers' techniques would be refined from rusty to exquisite. Let each bureau of Tianjin and Shanghai buy machines for manufacturing Remington bullets and imitated bullets, explosives, copper coils for support." Li Hongzhang's action was of epoch-making significance in the innovation of combat weapons in the late Qing period. In addition, in order to ensure the "the safety and facilitate transportation of guns, mines and other armaments, each arsenal is located at ports overlooking the river or nearby the seashore and is heavily guarded.".

\section{3. "Shipbuilding"}

This action can be divided into two parts: "defense" and "learning from foreigners".

"Defense" refers to the layer upon layer of defense against the warships. In the memorial, he said: "It is important to identify the degree of urgency and choose the particularly critical places. For example, the Dagu, Beitang, Shanhaiguan in Zhili Province, which are the gate of the capital and its environs and are the most important; The area from Wusong to Jiangyin of Jiangsu Province, is the gate of Yangtze River, and is secondarily important. This kind of classification is because the capital and its environs are the fundamental of China, while the Yangtze River is where the wealth gathers. As long as the secondarily important area can be guarded, with modest force deployments on other seaports along the border of each province, the overall situation will not be greatly influenced even though these less important deployments were thwarted." Therefore, Li Hongzhang proposed to purchase artillery shells, armored ships, mines and so on from the west and deployed in the capital and its environs, which was the most forefront area of the coastal defense (around the Bohai Sea area), and deployed the inferior domestically-made ship No.6, artillery shells in the Zhejiang and Fujian of Nanyang area. In the mid and late 1870s, under Li Hongzhang's vigorous leading and planning, the situation became more and more prosperous.

In some defense systems, soldiers and technicians were sent to study the seamanship, in order to cultivate technical backbones. This is the stage of "learning to make foreign implements."

\section{4. "Raising Fund"}

The construction of coastal defense involves the use of money. Li Hongzhang also took pains to do it.

First of all was the beginning of "dispute of coastal defense or land frontier defense". In view of the fact that China is protected by high mountains, the foreign powers cannot easily invade China from the land. Thus, the foreign powers actively developed their maritime forces in order to achieve the goal of invading China from the sea. On the other hand, the land frontier defense faction took Shanhaiguan, the birthplace of the Qing Dynasty, as its foothold, and emphasized the layer-upon-layer defense of Xinjiang, Mongolia and northeastern China to the capital. The ideas of both factions were and are of great significance for maintaining the integrity of China's territory and stability at home and abroad. Since the two factions stood up to each other as an equal, the Qing court appointed Zuo Zongtang to recapture the Xinjiang area quickly, and Li Hongzhang to plan the construction of the coastal defense. Because of shortage of funds for coastal defense, Li Hongzhang called for, "All troops that have gone out and have not yet gone out of the country must be slightly dissolved. Withdraw if they can withdraw and stop if they can stop. Then the saved money can be used for coastal defense." "Dispute of coastal defense or land frontier defense" not only promoted to retake Xinjiang, but also opened a new path for the construction of coastal defense in modern China.

Secondly, after approved by Ministry of Foreign Affairs, the Ministry of Revenue also appropriated funds to the construction of national coast defense. Li Hongzhang prevailed over the dissenting views of fetishistic feudal officials, and imitated western ways to set up modern companies, hire technicians, call up local people as labor force, and excavate industrial resources in Chinese mountains for the production of military equipment, which achieved self-sufficiency, saved the country by implements, and also solved the livelihood problems of common people. Li Hongzhang raised funds by increasing income and reducing expenditure, which greatly aroused the enthusiasm of the central ruling class and the local people for the construction of coastal 
defense and further promoted the development of the coastal defense in the late Qing Dynasty.

\section{5. "Employing Talents"}

This move is broadly divided into three parts.

(1) Each of the seven coastal provinces' coastal defense has its own emphasis and is different. Therefore, different capable personnel should be sent to lead according to different military conditions and cultures in each province. However, when fighting against the enemy, it is necessary to follow the central command, cooperate with the joint operations, and form a complete coastal defense system.

(2) Li Hongzhang recommended Shen Baozhen and Ding Richang to hold important posts. These two men were not only Li Hongzhang's right-hand men, but also experienced central figures in the coastal defense faction. They have made indelible contributions to the resolution of the Sino-Japanese conflict in 1874 and the construction of the coastal defense. Li Hongzhang did not stick to one pattern and entrusted important tasks to his subordinates, which showed that he attached great importance to talents. He was also a shrewd judge of character. He fancied Ding Richang's foresight to the implement innovation and Shen Baozhen's passion for the western culture, and then recruited them. Afterwards, In the SinoJapanese conflict, it was Shen Baozhen who suggested Li Hongzhang to use "illustrating power of army" to expel Japanese maritime forces forcibly occupying the southeastern sea, and to adopt method "notifying rules of Qing court" to intimidate Japan in negotiations.

(3) Adopt Shen Baozhen's suggestion of learning western culture, send personnel abroad to learn advanced instrument technology, and assign great responsibility to talents. Those returning talents later have all become the mainstays of China's coastal defense and even in the process of modernization.

\section{6. "Persistence"}

This move refers to the implementation of the coastal defense measures is a long and continuous exploration process.

Li Hongzhang, an important official in the late Qing Dynasty, was highly regarded by the rulers and had the highest position under the emperor. Even so, he appealed everyone to rise up and save themselves with persistence by using the past to satirize the present. Such persistence was mainly embodied in the above five stages, "training soldiers, upgrading weapons, shipbuilding, raising funds and employing talents", as Li Hongzhang said: "For countries in the west, originated in a tiny area, but have created all kinds of powerful implements, achieved such a high accomplishment within a hundred years, and planned with such a long-term view, isn't it the effect of the whole nation racking their brains to develop and everyone thinking of fighting for himself? Among the five main continents, China is always the most powerful one since ancient times. However, we are now despised by small countries. It is too late for now to train troops, make weapons, buy ships, or to learn from others' strengths to compensate our weakness." He took Japan, a small country in the East, and the Western countries despised by the Chinese for example, to call on Chinese people to build up their own coastal defense system by learning "western implements".

\section{THE INFLUENCE OF LI HONGZHANG'S COASTAL DEFENSE MEASURES ON LATER GENERATIONS}

As an important official of late Qing Dynasty, Li Hongzhang had absolute keen insight and judgment. Through the experience and lessons from the SinoJapanese conflict in the 1870 s, he realized the weakness of China's maritime power, and made vigorous efforts to turn the situation at this crucial point by putting forward the construction of China's coastal defense, which also had an impact on the construction of contemporary coastal defense.

\subsection{Positive Impact of Li Hongzhang's Coastal Defense Measures on Later Generations}

(1) It is a great enlightenment and influence on China's contemporary coastal defense construction. The core idea of "training soldiers" in his Discussion on Coastal Defense plays a leading role in the professional division of the contemporary sea arms, and the system of "sea-land cooperated operation" is also the rudiment of each country's development of armies and navies. Although "upgrading weapons" stays in the aspect of studying the foreign people's implements, but it alerted the military industry of later generations to innovate independently. The establishment of naval forces and ship deployment setting in "shipbuilding" directly affects the division of contemporary offshore navy and ocean navy. "Raising funds" is collecting the nationwide efforts to build a stable coastal defense system. "Employing talents" pays attention to making the best use of things, giving full play to talents' strengths, and avoiding stifling professional talents. "Persistence" precisely reflects the coastal defense construction is not built overnight, but a gradual process of continuous development.

(2) It, to some extent, reversed the situation of the late Qing Dynasty which was backward and bullied. Li Hongzhang's forward-looking view of the coastal defense construction is fully reflected from his Discussion on Coastal Defense. From then on, "from Mukden to Guangdong, along the coastline stretches thousands of miles locate numerous ports, which make it possible to store powerful troops everywhere in need."The stable 
coastal defense system of the 1870s was relying on heavy guards along over 30 thousand kilometers coastline to resist the enemy, which not only added a strong defense for the stability of the late Qing Dynasty prolonging its rule for 42 years (1912 Emperor Xuantong abdicated), but also effectively prevented the threat and infiltration of Japanese forces of aggression against the state power, as a force protection guaranteeing the rule of Qing Dynasty rule and resisting to Japanese aggression.

\subsection{Limitations of Li Hongzhang's Coastal Defense Measures}

(1) The term "implements" appeared many times in the Discussion on Coastal Defense is limited to learning western culture as Li Hongzhang structured in his coastal defense system for the late Qing Dynasty, especially stays on the surface of armament implement technology.Because China's ancient science and technology did not form a complete system and the Westernization Movement did not master the core technology of science and technology, the coastal defense faction, originated from the feudal bureaucrat, had to rely on completely imported Western-style weapons, and lost the ability to innovate and develop the military industry independently. It was defeated by Japan in the SinoJapanese War afterward because of two reasons. First, it relied on imitation and import of military equipment, but not mastered the core technology. Second, Li Hongzhang, as a feudal ruling class, could not completely break through the restriction of the system. Every measure in Discussion on Coastal Defense can affect the whole body. However, the situation of being beset by internal and external trouble made it inconducive for the late Qing Dynasty to construct the coastal defense. So, this is also the reason for the initial difficulties in the establishment of coastal defense in China, a land power country.

(2) Because it was the initial establishment of coastal defense, there were still many problems in the system of coastal defense_- the idea of "failure to govern in separate districts before war and to conduct a unified command during war". Although Li Hongzhang was the core of the leadership, his faction was divided into various groups, and they fought with each other either for power or interests. This kind of decentralized combat thinking has directly led to the lack of wartime supplies and flaws in naval defense military system during the Sino-Japanese War. It is advantageous to adjust measures according to local conditions, but central command should not be ignored.

\section{CONCLUSION}

From a comprehensive perspective, China's modern and contemporary coastal defense construction evolves from the massive land to the vast ocean, from the early construction of the coastal defense system in the late Qing
Dynasty to the construction of the modern navy. To reconstruct the coastal defense system, the Chinese people did take a hundred years. Japan's occupation of Ryukyu in the 19th century caused the ministers led by Li Hongzhang in the late Qing Dynasty to attach importance to the construction of China's coastal defense system, and gradually influenced the reconstruction of China's national defense structure. By analyzing the causes, changes, detailed contents and influences of $\mathrm{Li}$ Hongzhang's coastal defense measures under the conflict between China and Japan in the 1970s, it is a using of the past to study the present, and also a shallow exploration of the origin of China's century-old coastal defense.

\section{REFERENCES}

[1] Wei Yuan wrote, Li Julan annotated, Illustrated Gazetteer of the Countries Overseas: Learning Advanced Technology from Barbarians in order to Oppose Barbarians, 9787534817199, Henan: Zhongzhou Ancient Books Publishing House, 1992, p.1.

[2] Xue Xiaorong. “Country's Integration and Reconstruction of National Defense of Modern China in the Late Period of the Qing DynastyAnother Understanding of Dispute between Coast Defense and Frontier Defense" Exploration and Free Views. 2006.7:57--60

[3] Gao Chengjin. "The Contest between Land Frontier Defense and Seacoast Defense in Late Qing Dynasty and Its Referential Significance" Wuhan: Institute of Political Science, Central China Normal University, 2010.9

[4] Will Operation Red Sea cure Grand Secretariat's illness?

[5] [US] Hsu, Cho-Yun. Chinese Culture and World's Culture. Guiyang: People's Publisher in Guiyang, 1999

[6] Ma Ruxian. Frontier Policy of Qing Dynasty. Beijing: China Social Sciences Press.1994

[7] Joseph. S. Nye. Jr Understanding International Conflicts: An Introduction to Theory and History. Shanghai Century Publishing Group 2003

[8] Xie Jian. The Generation and Evolution of $\mathrm{Li}$ Hongzhang's Thought of Coast Defense. Journal of Sanming University. 2013.10

[9] Li Hongzhang. Discussion on Coastal Defense of Li Wenzhong Gong Quan Ji on December 10, 1874 [M]. Taipei: Wen Hai Press Company, 1980:19

[10] Li Xianbo and Deng Tingting. Analysis the Dispute on Diao-yu Island between China and Japan from International Law. Presentday Law Science. 2004.3 
[11] Guangxu Chao Donghua Lu (II). Beijing: Zhonghua Book Company, 1980:332

[12] [Qing] Sino-Japanese Provisions of Cordial Relations

[13] [Qing] Sino-Japanese Convention of Peking

[14] Liang Qichao. Li Hongzhang. Shaanxi Normal University Press 2009

[15] Gao Chang. Discussion on Li Hongzhang's Coast Defense Ideas From the Aspect of Ryukyu Island Issue. Journal of Jixi University, 2011 